\title{
Review design of wind load analysis structures guyed tension in the Bogor repeater radio frequency antenna towers
}

\author{
Sunaryo Cim (Main Author and Corresponding Author) \\ Engineering Management Science, Halu Oleo University \\ Kendari, 93111 (Indonesia) \\ 1@sunaryocim.com \\ https://orcid.org/0000-0001-7421-1167
}

\section{La Ode Muh. Magribi}

Engineering Management Science, Halu Oleo University

Kendari, 93111 (Indonesia)

obi_magribi@yahoo.com

https://orcid.org/0000-0001-7433-1433

\section{Adris A. Putra}

Engineering Management Science, Halu Oleo University Kendari, 93111 (Indonesia)

aputra_adris@yahoo.com

https://orcid.org/0000-0002-8516-2126

\section{Minson Simatupang}

Engineering Management Science, Halu Oleo University Kendari, 93111 (Indonesia)

minson.simatupang@uho.ac.id

https://orcid.org/0000-0002-8965-5251

\section{Muh. Thahir Azikin}

Engineering Management Science, Halu Oleo University Kendari, 93111 (Indonesia)

thahir.azikin@uho.ac.id

https://orcid.org/0000-0002-9889-7869

\section{Manuscript Code: 13974}

Date of Acceptance/Reception: 01.10.2020/24.12.2019

DOI: 10.7764/RDLC.19.3.381

\begin{abstract} be lifted and friendly, it will cause waste.

Keywords: Guyed tension, wind loads, antenna towers, triangle type, Square type.
\end{abstract}

The purpose of this study is to analyze the RRF antenna tower under wind load action, the wind load is viewed from an angle of $0^{\circ}$ to the towing cable to the largest angle on the two types of antenna towers, triangle and Square. Both types will produce different wind loads so that we can find out which load is the biggest from a combination of wind directions. The research method is by empirical analysis, calculating the wind load alone while other loads are not counted. As a result of wind loads, the tension cable and load direction correspond to each section and then the resultant values of force and direction will arise. And finally, the force is changed to lift and the anchor will hold the force. The results use of triangle antenna towers is more beneficial, because the wind load that occurs is smaller, thus the construction costs are also smaller. Due to the wind load that works horizontally and will be provided by the tower that stands vertically, the tower requires several retaining cables in a diagonal position, the force that propagates on the diagonal cable will cause a force in the vertical direction or lift, so the lift must be placed using anchors that are embedded in the soil, the large load from the soil that will hold the anchor is determined based on the value of the analysis, the criteria are too light so the anchor will

\section{Introduction}

The loss of guy tension can actually increase the axial force on the antenna tower due to wind load (Luzardo et al., 2012), however, the guy tension variation does not correspond to a very significant axial variation, and an increase in the cable pre-tension force can produce pole frequencies and it is expected that variations in structural response to the loaded dynamic. In this study, the focus is very much on pile construction due to wind loads that are held by cables that withstand tension according to the position and angle installed in the construction, so that the workload can be controlled by cables that are installed simultaneously. Not only that in this study also calculated the load of the cable to the wind direction starting from $0^{\circ}, 60^{\circ}$ and $90^{\circ}$, based on this wind direction, the cable tension will work according to 
the conditions, in this study for the $0^{\circ}$ wind direction the load is divided into two, while for wind direction $60^{\circ}$ then the tension will be held by one of the cables, thus the wind direction will determine the value of the tension for each cable.

Failure due to tower wind loads is determined using the Maximum Tension Theory (Alshurafa \& Polyzois, 2018), in this type of loading model receives wind loads according to the maximum conditions that occur. The taller the tower, the greater the wind load received by the tower, thus the tower requires a cable to withstand the horizontal forces that occur. Besides the wind load is also influenced by the dead load. Thus, each antenna has been determined that the load to be carried must not exceed the permitted capacity.

The transmitter antenna tower requires a detailed analysis, especially the influence of wind loads, dead loads, and other loads received by the construction of the loading analysis method using finite elements (Alshurafa, Alhayek, and Polyzois 2019), in this planning the triangular antenna tower does not use rope cables, including holding wind load by using the frame itself or self-supporting towers, the frame must be able to withstand tensile and compressive loads, with wind loads coming from various directions ranging from $0^{\circ}, 60^{\circ}$ and $90^{\circ}$. The wind load will be held by the tower without wires using only the tangka rod that functions as a frame press and pull frame. This is due to the construction using stronger diagonal, horizontal and vertical bars. This type of tower can be made with a triangle or Square construction, usually adjusted to the dead load that will burden it, to carry a very heavy load then construction is usually made with rectangles and for light loads, the construction is made triangle only.

Structural analysis of guyed steel telecommunication towers for radio antennas is an antenna structure construction that uses the towing cable as reinforcement (Oliveira et al., 2007), this analysis is the construction between dead load and wind load combined to get strong planning, use angle profile iron dominates this construction, thus due to wind load is very large compared to dead load. The use of the towing cable is still used only the direction of the wind is not made into a variable in this study, it is most likely taken the most extreme wind direction, so it does not take into account in detail. In addition to steel material, for any type of tower, this is because the connection greatly determines the strength of the construction, all loads will be collected at the node, thus requiring very strong connection handling. The length of each compressive rod both diagonally and horizontally is also taken into account, if the load gets bigger the node will get shorter, and vice versa.

Working wind speed and charged to tension in guy wire tower type construction (Angadi \& Prashanth, 2017), due to this wind load the construction will work according to the load received, the tower truss construction will accept the load, based on the speed that occurs, this loading is utilized to design truss constructions. To determine the design of each loading component, it greatly influences the results of the dimensions to be used.

Climatic conditions in an area greatly affect the antenna tower model (Barsoum \& Barsoum, 2012), this is largely determined by the wind direction conditions in an area so that the antenna tower model must be adjusted to the suitable model conditions. Analysis of wind loads and snow loads using SAP2000 software (Xiaowei et al., 2016) (Marjanović \& Petronijević, 2019), apparently it still keeps in the direction of the wind from various directions and will be accepted by the triangle-shaped construction. On the basis of this study, it is assumed that the wind starts in the direction of the cable and the furthest from the cable tension.

In addition to wind loads, there are also combinations with additional snow loads (Erdem, 2015), this type of tower type is strongly influenced by other load combinations such as snow loads and other loads. This combination of loading only applies to subtropical regions and does not apply to tropical regions. For the tropics, the analysis for loading enough wind loads and a combination of live and dead loads and for snow loads is ignored. But still, pay attention to the direction of the wind from various directions.

The wind load received by the antenna tower is assumed to be in the direction, coming from $0^{\circ}$ to $90^{\circ}$ with the addition of the antenna tray area (Bezrukovs et al., 2017). It's just not counted against the slope of the antenna mast triangles. If the wind originates from 0 then the wind will be held back by the antenna frame in the horizontal trunk and diagonal truss conditions, and if the wind direction comes from $90^{\circ}$ then the wind will be held back by the tower with rocks with two diagonal cables on both sides.

The tower guyed tension-type cylindrical mast which gets wind loads from various directions is less accepting the influence of wind loads (Pezo et al., 2018), this is strongly influenced by the aerodynamic model of the cylindrical frame made by the cylinder. It's just that cylindrical antenna poles are rarely made by reducing the dead weight of the pole itself. If it can be reduced, then the wind load that hits the cylindrical pole with a hollow condition will be somewhat lighter the wind load that hits. 
The force is an action of an object against another object and is generally characterized by a point, its magnitude, and direction, the magnitude of the force is characterized by a number of Newton units $(\mathrm{N})$ and multiples of kilonewton (kN) mathematically written $1000 \mathrm{~N}$. However, a force acting on a particular particle has the same point. The direction of force and the understanding of force are represented by a line of arrows. The line of the arrow is straight without limits where the force of action and is determined by the angle formed by the force, is explained in Figure 1. A force drawn in the line of the arrow is determined by the scale or length of the arrow. In two forces that have the same magnitude and the same active line but are drawn differently as in Figures 1.a and 1.b, it will have the opposite effect directly on a particle (Beer et al., 2013).

Figure 1 The direction of force, Source: (Beer et al., 2013)

(a)

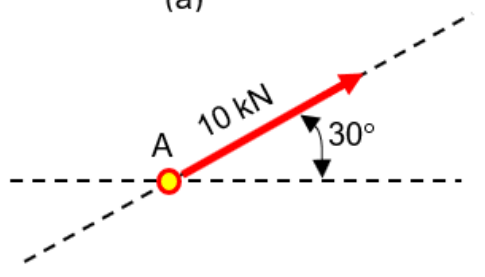

(b)

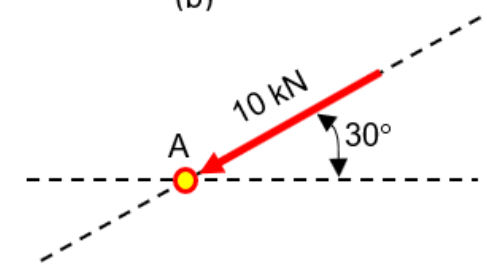

In experiments two forces $P$ and $Q$ acting on particle $A$ (Figure 2.a) can be replaced by one $R$ force which has the same effect on particles (Figure 2(c)). This force is called the resultant of the $P$ and $Q$ forces, in Figure 2(b), a parallelogram will form, on the use of $P$ and $Q$ as two sides of the adjacent parallelogram. The diagonal line that passes through $A$ is the result. Thus the way to find this resultant, known as the parallelogram law for the addition of two forces. The law can be proven experimentally, but it cannot be proven or derived mathematically.

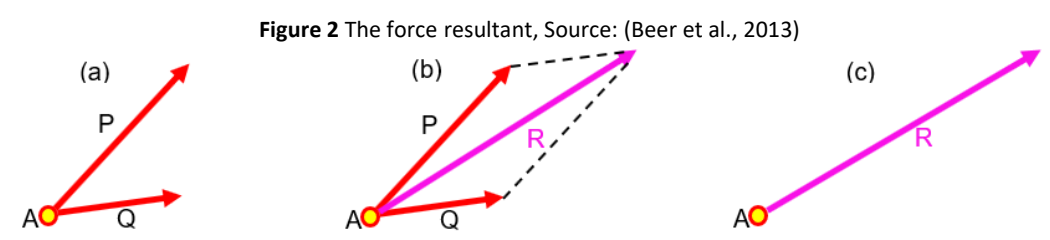

A vector is a force that cannot be added in ordinary arithmetic or algebraic definitions, two forces acting at a certain angle and the strength of a particular force to experience the addition of a certain force. Force strength is not just the amount of force that follows the rules or laws of adding parallelograms, displacement, speed, acceleration, and momentum is another example of a physical quantity that has magnitude and direction added according to the laws of a parallelogram. All the forces that occur are not represented by using a mathematical vector, while the physical amount has a magnitude but does not have a direction, for examples such as volume, mass or energy which is usually symbolized by numbers or scalars. Vectors are defined as mathematical equations that have values and directions, which add them according to parallelogram laws. The vector owned by the arrow in the illustration and will be distinguished from the number of scalars denoted by the letter $\mathrm{P}$. The vector is symbolized by giving an arrow above the letter $\overrightarrow{\mathrm{P}}$ or by giving an underscore $\underline{P}$.

The vector used to represent the force acting on a particular particle has a clear point of application, namely the particle itself. Such vectors are called fixed or bound vectors and cannot be moved without changing the problem conditions. Two vectors that have the same magnitude and direction are said to be the same vector, as in Figure 3(a), and thus can be symbolized by the same letter.

$A$ vector is said to be negative from a vector $P$ which is defined as a vector whose magnitude is equal to $P$ but the direction is opposite to $P$, as, in Figure $3(b)$, the negative value of the vector $P$ is denoted by - $P$. Thus the vectors $P$ and $-P$ are generally called equal and opposite directions, in the mathematical equation described as follows: $P+(-P)=0$

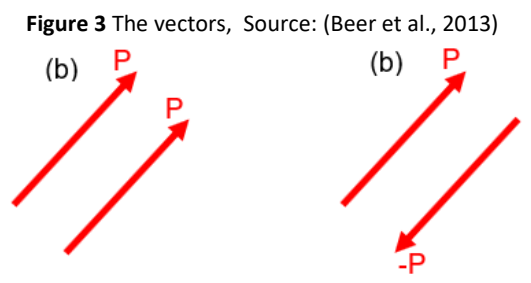

The addition of vectors is defined using the parallelogram law, that the sum of the two vectors $P$ and $Q$ is obtained from 
two vectors from point $A$ and forms the parallelogram of $P$ and $Q$ (Figure 4(a)). The diagonal line that passes through point $A$ is the sum of vectors $P$ and $Q$, this number is added to $P+Q$. Thus the + sign is used to show vectors and scalar addition, this proves that vectors and scalars are always different. For this reason, the magnitude of the $P+Q$ vector is not generally the same as the number of $P+Q$ from the size of the $P$ and $Q$ vectors. Therefore the parallelogram formed from $P$ and $Q$ does not depend on the order of selection of $P$ and $Q$. commutative, mathematically written as follows:

$P+Q=Q+P$

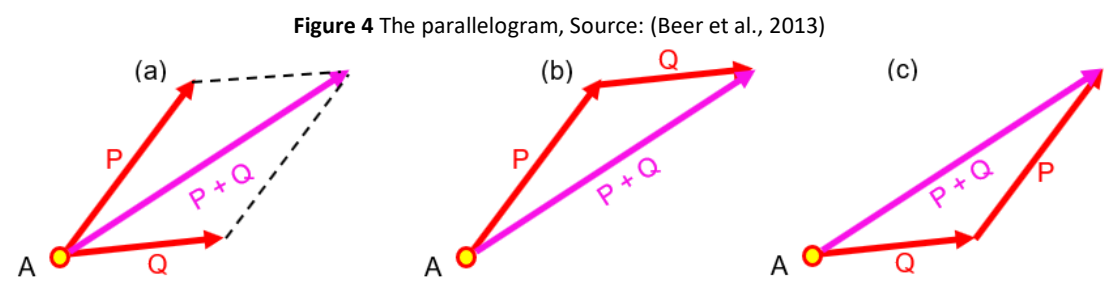

Based on the parallelogram, the lin method for determining the number of two vectors is to use the triangle method, with the description as follows: seen in Figure 4(a), where the number of $P$ and $Q$ vectors has been determined by the parallelogram law. Because the sides of the parallelogram opposite $Q$ and $Q$ also have magnitudes and directions, thus the parallelogram is only half drawn (see Figure $4(b)$ ). The addition of two vectors can be done by adjusting $P$ and $Q$ by connecting the ends of $P$ and $Q$ (see Figure $4(c)$ ), this is called adding cumulative vectors. For vector, the reduction is defined as the addition of the corresponding negative vector. Then the vector $P+Q$ represents the difference between the vector $P$ and $Q$ obtained by adding to the negative vector $P$ - $Q$ (see Figure 5 ), mathematically written as follows:

$P-Q=P+(-Q)$

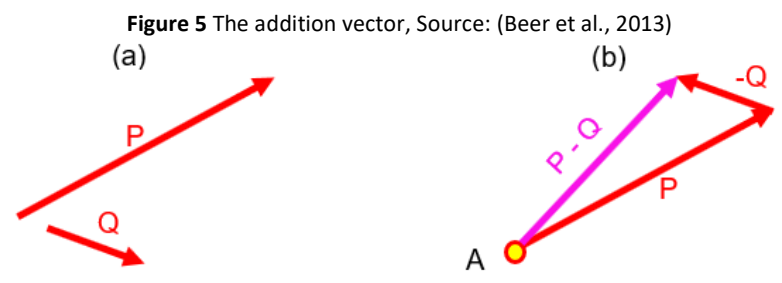

A force that works which is influenced by a certain angle, will experience an increase in force due to the magnitude of the angle that occurs (Bird \& Ross, 2015), so mathematically it can be solved with a triangular equation and can use the sine, cosine, tangent, and Pythagorean theorem approaches, mathematically can be explained as follows:

resultant, $R=\sqrt{a b^{2}+b c^{2}}$

Where:
$\mathrm{ac}=$ resultant $(\mathrm{R})$, hypotenuse
$a b=$ opposite side
$\mathrm{bc}=$ adjacent side

(1)

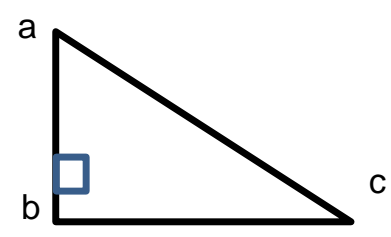

Equation (1) is used to find the length of the radius of $\mathrm{R}$ in each segment, then it will be used to determine the angle that occurs at both angles other than the right angle. Based on this equation, the following derivative equation will appear:

$\mathrm{F}_{0-10}=\left[\frac{\mathrm{h}}{2}\right]$ g.w.csc. $\left(\mathrm{d} \cdot\left[\frac{\mathrm{w}_{0-10}}{360}\right] \cdot 2 \cdot\left[\frac{\mathrm{r}}{2}\right] \pi \cdot 1 \cdot 5\right.$

Where:

$\mathrm{F}_{0-10}=$ the force that occurs is the influence of the wind direction (Newton), force square tower

$\mathrm{h}=$ tower height per segment $(\mathrm{m})$

$\mathrm{g}=$ gravity $\left(\mathrm{m} / \mathrm{s}^{2}\right), 9.8067 \mathrm{~m} / \mathrm{s}^{2}$ 


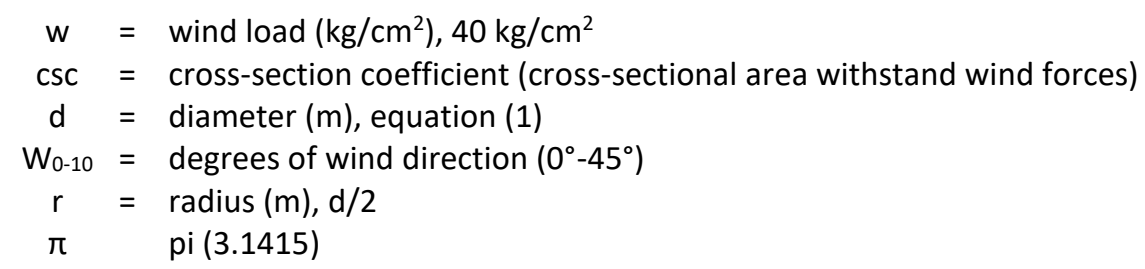

$\mathrm{F}_{\mathrm{tt}}=\frac{\mathrm{b}_{2}}{2} \cdot h \cdot w \cdot g \cdot \csc$

Where:

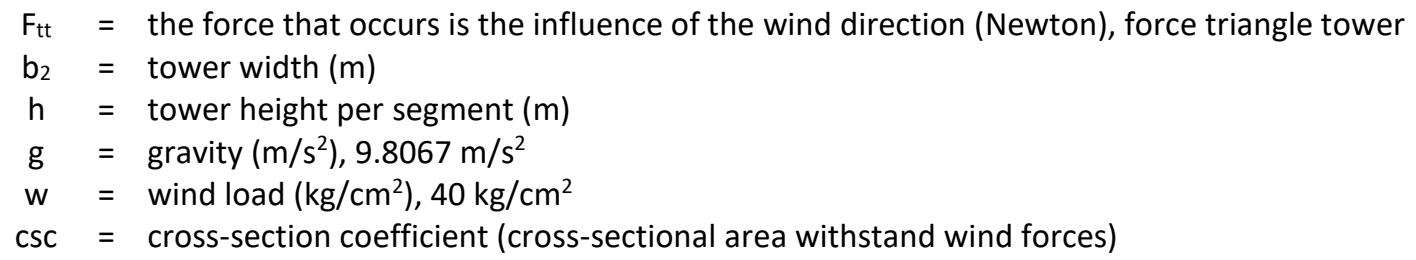

A force that acts on a rod, either in a horizontal position or in a vertical position, then this force acts on the first level or segment and has not been influenced by external forces, so this principle is usually called the primary moment (Bird \& Ross, 2015), based on the effect of the working primary moment, then the force configuration will occur according to the conditions that occur, including a force that works and is influenced by a certain angle, mathematically the primary moment equation can be described as follows:

$\mathrm{M}_{\text {primer }}=\frac{3}{4} \cdot \mathrm{h} \cdot \mathrm{F}_{\mathrm{w}}$

Where:

Mprimary $=$ primary moment $(\mathrm{Nm})$

$\mathrm{h}=$ tower height per segment $(\mathrm{m})$

$F_{w}=$ the force that occurs is the influence of the wind direction (Newton), equation (1) \& (2)

$M_{\text {angle }}=r \cdot h$

(5)

Where:

$\mathrm{M}_{\text {angle }}=$ corner moment $(\mathrm{Nm})$

$r \quad=\operatorname{radius}(\mathrm{m}), \mathrm{d} / 2$

$\mathrm{h}=$ tower height per segment $(\mathrm{m})$

$F_{N}=\frac{M_{\text {primer }}}{M_{\text {angle }}}$

Where:

$\mathrm{F}_{\mathrm{N}}=$ normal force $(\mathrm{Nm})$

$\mathrm{M}_{\text {primary }}=$ primary moment $(\mathrm{Nm})$, equation (4)

$\mathrm{M}_{\text {angle }}=$ corner moment $(\mathrm{Nm})$, equation (5)

$R_{x y}=\sqrt{\sum R_{x}^{2}+\sum R_{y}^{2}}$

Where:
$R_{x y}=$ resultant force $(\mathrm{Nm})$
$\Sigma R_{x}=$ sigma force $x$ direction $(\mathrm{Nm})$
$\Sigma R_{y} \quad=$ sigma force $y$ direction $(\mathrm{Nm})$

$\left(\mathrm{R}_{\mathrm{xy}}\right) \mathrm{Y}^{\circ}=\operatorname{Arctan} \frac{\sum \mathbf{R}_{\mathbf{x}}}{\sum \mathbf{R}_{\mathbf{y}}}$

Where:

$\left(R_{x y}\right) Y^{\circ}=$ number of degrees $Y$ direction $\left({ }^{\circ}\right)$

Arctan $=$ number of degrees $(\operatorname{atan}) \times \operatorname{direction}(\mathrm{Nm})$ 
$\Sigma R_{x} \quad=$ sigma force $x$ direction $(\mathrm{Nm})$

$\Sigma R_{y} \quad=$ sigma force $y$ direction $(\mathrm{Nm})$

$\left(R_{x y}\right) X^{\circ}=\operatorname{Arctan} \frac{\sum \mathbf{R}_{\mathbf{y}}}{\sum \mathbf{R}_{\mathbf{x}}}$

Where:

$\left(R_{x y}\right) X^{\circ}=$ number of degrees $X$ direction $\left({ }^{\circ}\right)$

Arctan $=$ number of degrees (atan) $x$ direction $(\mathrm{Nm})$

$\Sigma R_{x}=$ sigma force $x$ direction $(\mathrm{Nm})$

$\Sigma R_{y}=$ sigma force $y$ direction $(\mathrm{Nm})$

$\theta=\left(R_{x y}\right) Y^{\circ}+\left(R_{x y}\right) X^{\circ}$

Where:

$\theta=$ Total of degrees $\left({ }^{\circ}\right)$

$\left(R_{x y}\right) Y^{\circ}=$ number of degrees $Y$ direction $\left({ }^{\circ}\right)$, equation (8)

$\left(R_{x y}\right) X^{\circ}=$ number of degrees $X$ direction $\left({ }^{\circ}\right)$, equation (9)

$N=\sqrt{\Sigma X^{\circ 2}+\Sigma Y^{\circ}}$

Where:

$\mathrm{N}=$ normal force $(\mathrm{Nm})$

$\left(R_{x y}\right) Y^{\circ}=$ number of degrees $Y$ direction $\left({ }^{\circ}\right)$, equation (8)

$\left(R_{x y}\right) X^{\circ}=$ number of degrees $X$ direction $\left({ }^{\circ}\right)$, equation (9)

$W=$ sd.g.h.a

Where:

$\begin{aligned} \mathrm{W} & =\text { Anchor load (Newton) } \\ \mathrm{sd} & =\text { Soil density }\left(\mathrm{kg} / \mathrm{m}^{3}\right) \\ \mathrm{g} & =\text { Gravity }\left(\mathrm{m} / \mathrm{s}^{2}\right) \\ \mathrm{h} & =\text { Depth of anchor }(\mathrm{m}) \\ \mathrm{a} & =\text { Anchor Area }\left(\mathrm{m}^{2}\right)\end{aligned}$

The research method is analysis, calculating the wind load alone while other loads are not counted. As a result of wind loads, the tension and load direction correspond to each section and then the resultant values of force and direction will arise. And finally, the force is changed to lift and the anchor will hold the force.

\section{Results and Discussion}

This research only focuses on the wind load, in Figure 6.a and 6.b show a tower construction of a Repeater-RadioFrequency (RRF) antenna in the form of a triangle. And in Figure 6(c) shows an illustration of the antenna tower construction model with a height of 30 meters and the profile or dimension of the pole $30 \mathrm{~cm} \times 30 \mathrm{~cm}$. As a result of the wind load, it will be analyzed triangle or the largest Square type receives wind load, thus based on this analysis it will be known which is the most beneficial of the two types of antenna towers.

Based on Figure 6(b), the mainframe will not be able to stand alone without being pulled using tension cable, thus the cable tension will occur to provide a balance so that the antenna tower can stand upright and strong. Logically, the cable that pulls the tower antenna gets stronger the more cable tension occurs. But in detail will be explained on this occasion.

The antenna tower in an illustration and construction description, to be more clearly described as follows (Figure 7). 
Figure 6 (a). The Bogor Repeater-Radio-Frequency (RRF), (b) The Illustration antenna tower, Self-elaboration.

(a)

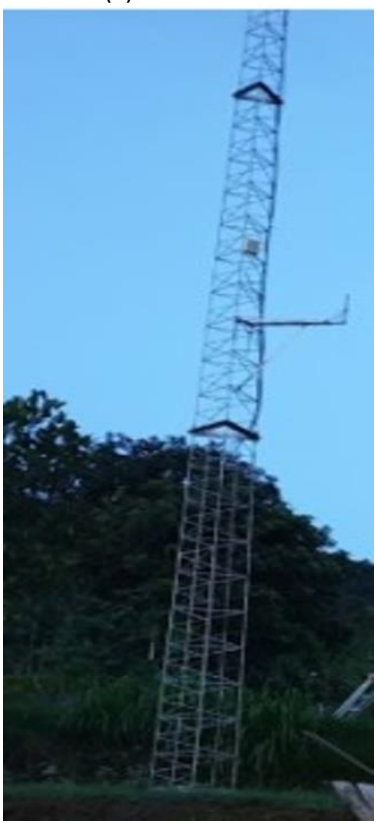

(b)

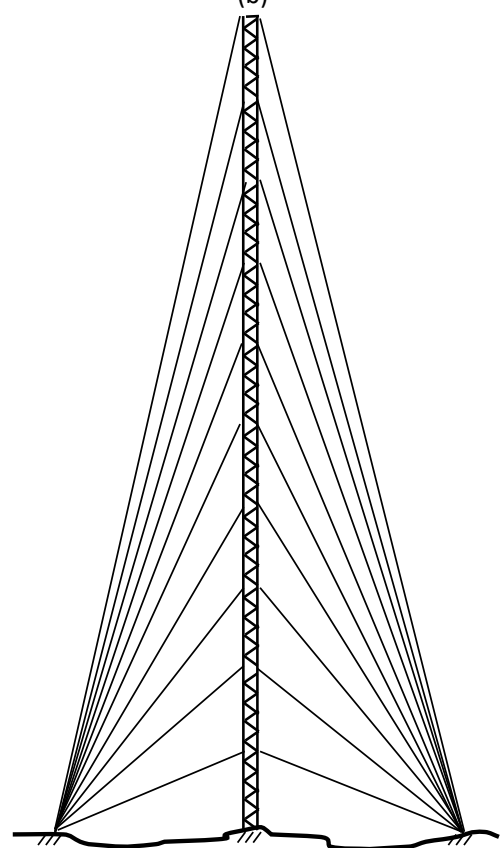

Figure 7(a) The dimensions of the tower cable, (b) Square tower cross-section, (c) Triangle tower cross-section. Source: Self-elaboration.

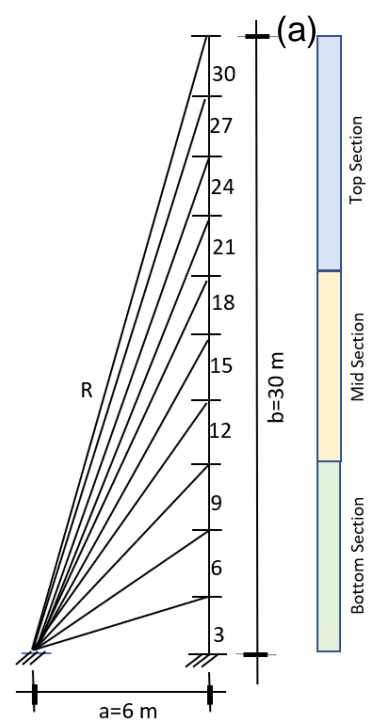

(b)

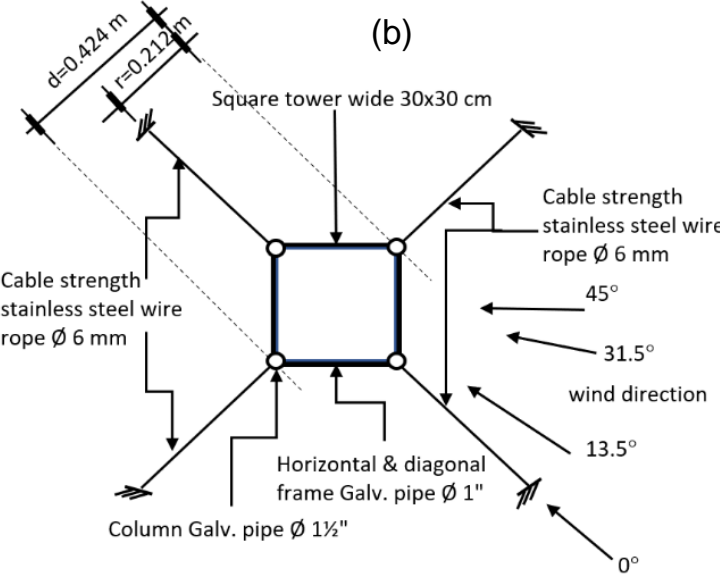

(c)

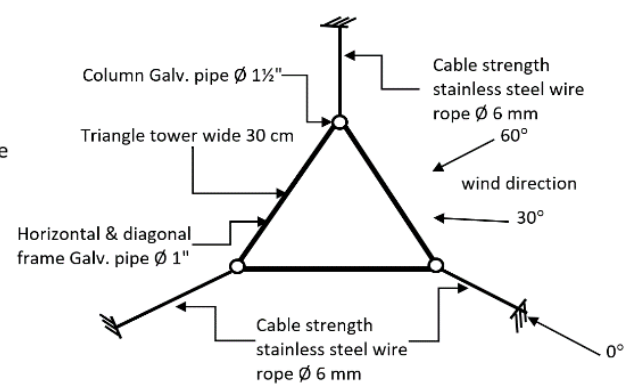

Based on Figure 7(a) is an illustration of antenna tower with a height $b=30$-meters, consisting of 10 segments, and each segment, the antenna tower poles are pulled with 10 cables in each segment (R), with distance (a) from the tower antenna mast.

Based on Figure 7(b) is a Square antenna tower pole piece, the tower is pulled by 4 sides of the cable, it is assumed that the wind will come from $0^{\circ}$, then there is one side of the cable that will withstand $100 \%$ of the wind load that occurs. And it is assumed that the wind will come from the direction of $45^{\circ}$, As a result of the wind direction coming from the $45^{\circ}$ direction, the wind load will be held by the two cables, only $50 \%$ of the total wind load that occurs. It turns out that the wind is coming from the $0^{\circ}$ direction then the area of the tower that will withstand winds as wide as a diagonal rectangle or (d) and if the wind direction comes from $45^{\circ}$ then the width is equal to the width of the tower frame.

Based on Figure 7(c) is a triangular piece of antenna tower poles, the tower is pulled by 3 sides of the cable, it is assumed that the wind will come from $0^{\circ}$, then there is 1 side of the cable that will withstand $100 \%$ of the wind load that occurs. And it is assumed that the wind will come from the $60^{\circ}$ direction, then there are 2 sides of the cable that will withstand $50 \%$ of the wind load that occurs. It turns out that the wind coming from the $0^{\circ}$ direction then the area of the tower that will withstand winds as wide as the framework of the tower and when the wind direction comes from $60^{\circ}$ then the width is the same as the width of the tower frame as well. 
Based on Figure 7(a), (b) and (c) of the Radio Frequency Repeater (RRF) tower antenna with a height of 30-meters, there are generally two types, the first being the triangle type and the square type. Each of these types has several advantages and disadvantages. Table 1 explained and described as follows (Table 1).

Table 1. Wind load distribution, Source: Self-elaboration.

\begin{tabular}{|c|c|c|c|c|c|c|c|c|c|c|c|c|c|c|c|c|}
\hline \multirow[b]{2}{*}{$\begin{array}{l}\mathrm{N} \\
\mathrm{O}\end{array}$} & \multirow[b]{2}{*}{$\begin{array}{l}\text { Section } \\
\text { Tower }\end{array}$} & \multirow[b]{2}{*}{$\begin{array}{l}\csc \\
\left({ }^{\circ}\right)\end{array}$} & \multicolumn{8}{|c|}{ Compressive strength and degree of wind direction (Newton) } & \multicolumn{6}{|c|}{ Information } \\
\hline & & & $\begin{array}{l}\mathrm{W}_{0} \\
0^{\circ}\end{array}$ & $\begin{array}{c}W_{1} \\
4.5^{\circ} \\
\end{array}$ & $\begin{array}{l}W_{2} \\
9^{\circ}\end{array}$ & $\begin{array}{c}W_{3} \\
13.5^{\circ}\end{array}$ & $\begin{array}{l}W_{4} \\
18^{\circ}\end{array}$ & $\begin{array}{c}W_{5} \\
22.5^{\circ}\end{array}$ & $\begin{array}{l}W_{6} \\
27^{\circ}\end{array}$ & $\begin{array}{l}W_{7} \\
31.5^{\circ}\end{array}$ & $\begin{array}{l}W_{8} \\
36^{\circ}\end{array}$ & $\begin{array}{r}W_{9} \\
40.5^{\circ}\end{array}$ & $\begin{array}{l}W_{10} \\
45^{\circ}\end{array}$ & Discription & Value & Unit \\
\hline A & Square & & & & & & & & & & & & & Gravity (g) & 9.806 & $\mathrm{~m} / \mathrm{s}^{2}$ \\
\hline 1 & Top & 0.2 & $\begin{array}{r}49.2 \\
0\end{array}$ & $\begin{array}{r}48.4 \\
5\end{array}$ & $\begin{array}{r}45.9 \\
8\end{array}$ & $\begin{array}{c}45.5 \\
1\end{array}$ & $\begin{array}{r}44.0 \\
4\end{array}$ & $\begin{array}{r}42 . \\
57\end{array}$ & 41.10 & 39.10 & 38.17 & $\begin{array}{c}36.7 \\
0\end{array}$ & $\begin{array}{r}35.2 \\
3\end{array}$ & Wind load (w) & 40 & $\mathrm{Kg} / \mathrm{m}^{2}$ \\
\hline 2 & Mid & 0.25 & $\begin{array}{r}62.4 \\
0\end{array}$ & $\begin{array}{r}60.5 \\
7\end{array}$ & $\begin{array}{r}56.7 \\
3\end{array}$ & $\begin{array}{c}56.8 \\
9\end{array}$ & $\begin{array}{r}55.0 \\
6\end{array}$ & $\begin{array}{r}53 . \\
22\end{array}$ & 51.38 & 49.54 & 47.71 & $\begin{array}{c}45.8 \\
7\end{array}$ & $\begin{array}{r}44.0 \\
3\end{array}$ & Wide (b1) & 30 & $\mathrm{~cm}$ \\
\hline 3 & Bottom & 0.3 & $\begin{array}{r}74.8 \\
9\end{array}$ & $\begin{array}{r}72.6 \\
8\end{array}$ & $\begin{array}{r}70.4 \\
8\end{array}$ & $\begin{array}{c}68.2 \\
7\end{array}$ & $\begin{array}{r}66.0 \\
7\end{array}$ & $\begin{array}{r}63 . \\
86\end{array}$ & 61.66 & 59.25 & 57.25 & $\begin{array}{c}55.0 \\
5\end{array}$ & $\begin{array}{r}52.8 \\
4\end{array}$ & Wide (b2) & 30 & $\mathrm{~cm}$ \\
\hline B & Triangle & & & & & & & & & & & & & High (h) & 3 & M \\
\hline 1 & Top & 0.2 & $\begin{array}{r}35.3 \\
0\end{array}$ & & & & & & & & & & & Diameter (d) & 0.42 & M \\
\hline 2 & Mid & 0.25 & $\begin{array}{r}44.1 \\
3\end{array}$ & & & & & & & & & & & Radius $(r)=d / 2$ & 0.21 & $\mathrm{~m}$ \\
\hline 3 & Bottom & 0.3 & $\begin{array}{r}52.9 \\
5 \\
\end{array}$ & & & & & & & & & & & Wide Triangle b2 & 30 & $\mathrm{~cm}$ \\
\hline
\end{tabular}

Based on Table 1, the 30-meter square antenna type tower consists of 3 sections, bottom section, middle section and top section, this section division is to distinguish the construction of iron poles in the lower section which is bigger and heavier than the middle and top sections. It is planned to reduce wind load and dead load so that it is given a coefficient or cross-section-coefficient (csc) value, csc is the cross-sectional area of a tower that withstands the wind, the lower the cross-sectional area upward, the coefficient value can be assumed alone, which is important, don't reverse it. The wind load from the direction of $\mathrm{W}_{0} 0^{\circ}$ values obtained are $49,92 \mathrm{~N}, 62.40 \mathrm{~N}$, and $74.89 \mathrm{~N}$, because the cable will withstand $100 \%$ without being helped or shared with other cables, this is because the wind direction comes parallel to the cable. The wind load from $\mathrm{W}_{5}$ direction $22.5^{\circ}$ or as a central point values obtained are $42.57 \mathrm{~N}, 53.22 \mathrm{~N}$ and $63.86 \mathrm{~N}$ and the wind load from $\mathrm{W}_{10}$ direction $45^{\circ}$ values are obtained $35.23 \mathrm{~N}, 44.02 \mathrm{~N}$ and $52.845 \mathrm{~N}$. At $\mathrm{W}_{10} 45^{\circ}$ the value obtained is apparently the smallest, this is due to the cross-section of the tower if the wind comes from $W_{10} 45$ the width of the tower is as wide as $b_{1}$ or $b_{2}$. Whereas if from the direction of $W_{0} 0^{\circ}$ tower the width of the tower is as wide as $d$. The second part is the Triangle type antenna tower from wherever the wind direction does not change the cross-sectional width so that it is called a constant or fixed value and the values obtained are $35.30 \mathrm{~N}, 44.13 \mathrm{~N}$ and $52.95 \mathrm{~N}$.

Once known and described in table 1 above, then the primary moment value will be sought in the type of square tower in each wind direction. The details are described in table 2 as follows (Table 2).

\begin{tabular}{|c|c|c|c|c|c|c|c|c|c|}
\hline \multirow[b]{2}{*}{$\begin{array}{c}\text { Distance, } \\
\mathrm{m}(\mathrm{a})\end{array}$} & \multirow[b]{2}{*}{$\begin{array}{l}\text { Segment, } \\
\text { m (b) }\end{array}$} & \multirow[b]{2}{*}{$\begin{array}{c}\text { Radius, } \\
\mathrm{m}(\mathrm{R})\end{array}$} & \multicolumn{2}{|c|}{ Angle } & \multirow[b]{2}{*}{$\begin{array}{l}\text { Wind Load } \\
\qquad W_{0}\end{array}$} & \multicolumn{2}{|c|}{ Moment } & \multirow{2}{*}{$\begin{array}{c}\text { Force } \\
\text { (Newton), } \\
\mathrm{N}\end{array}$} & \multirow{2}{*}{ Information } \\
\hline & & & $\operatorname{Sin} \alpha^{\circ}$ & $\begin{array}{l}\text { Radians } \\
\alpha^{\circ}(\mathrm{Rd})\end{array}$ & & $\begin{array}{c}\text { Mprimar } \\
y\end{array}$ & $M_{\text {angle }}$ & & \\
\hline 6 & 30 & 30.59 & 11.31 & 0.19 & 35.30 & 79.43 & 0.59 & 134.13 & \\
\hline 6 & 27 & 27.65 & 12.52 & 0.21 & 35.30 & 79.43 & 0.65 & 121.08 & \\
\hline 6 & 24 & 24.73 & 14.03 & 0.24 & 35.30 & 79.43 & 0.73 & 108.08 & \\
\hline 6 & 21 & 21.84 & 15.94 & 0.27 & 35.30 & 79.43 & 0.83 & 95.14 & \\
\hline 6 & 18 & 18.97 & 18.43 & 0.32 & 41.13 & 99.29 & 0.96 & 102.86 & \\
\hline 6 & 15 & 16.15 & 21.80 & 0.38 & 41.13 & 99.29 & 1.14 & 86.98 & \\
\hline 6 & 12 & 13.41 & 26.56 & 0.46 & 41.13 & 99.29 & 1.39 & 71.38 & \\
\hline 6 & 9 & 10.81 & 33.69 & 0.58 & 52.95 & 119.15 & 1.76 & 67.54 & \\
\hline 6 & 6 & 8.48 & 45.00 & 0.78 & 52.95 & 119.15 & 2.35 & 50.56 & \\
\hline 6 & 3 & 6.70 & 63.43 & 1.10 & 52.95 & 119.15 & 3.32 & 35.87 & \\
\hline
\end{tabular}

Based on Table 2, the value $134.13 \mathrm{~N}$ is obtained as the wind load that occurs at the top of the tower with a height of 30 -meters, the value of $35.87 \mathrm{~N}$ is the wind load that occurs at the top of the tower with a height of 3 meters and the value of 0 (zero) does not influence the wind load. Graphically it is shown in Figure 8(a). Why is each segment made with a length of 3 meters, this is analytically so that the tower can stand upright with a total height of 30 meters, a cable must be drawn with a segment every 3 meters, the closer the segments are, the sturdier but waste there is a segment with a distance of 4 meters or more, of course, this is not very sturdy. Practically, with a segment length of 3 meters, it will be easier to carry out an erection because it is lighter than the segment length of 4 meters.

The force influence of wind load on a triangle tower. The force caused by the influence of the direction of the wind load is a variable according to where the wind direction comes from, if it comes from 0 then the wind will be borne $100 \%$ by cable-strength. For square towers will be described and explained in the following Table 3. 
Table 3. The triangle tower cable-strength influence on the direction of the wind load. Source: Self-elaboration.

\begin{tabular}{|c|c|c|c|c|c|c|c|c|c|c|c|}
\hline \multirow{3}{*}{$\begin{array}{c}\text { Segment, } \\
\mathrm{m}(\mathrm{b})\end{array}$} & \multirow{3}{*}{$\begin{array}{c}\text { Cable } \\
\text { strength, } \\
\mathrm{N}\end{array}$} & \multicolumn{10}{|c|}{ The triangle tower cable-strength influence on the direction of the wind load } \\
\hline & & $6^{\circ}$ & $12^{\circ}$ & $18^{\circ}$ & $24^{\circ}$ & $30^{\circ}$ & $36^{\circ}$ & $42^{\circ}$ & $48^{\circ}$ & $54^{\circ}$ & $60^{\circ}$ \\
\hline & & 5 & 10 & 15 & 20 & 25 & 30 & 35 & 40 & 45 & 50 \\
\hline 30 & 134.13 & 127.43 & 120.72 & 114.01 & 107.31 & 100.60 & 93.89 & 87.18 & 80.48 & 73.77 & 67.06 \\
\hline 27 & 121.08 & 115.03 & 108.97 & 102.92 & 96.87 & 90.81 & 84.76 & 78.70 & 72.65 & 66.59 & 60.54 \\
\hline 24 & 108.08 & 102.67 & 97.27 & 91.87 & 86.46 & 81.06 & 75.65 & 70.25 & 64.85 & 59.44 & 54.04 \\
\hline 21 & 95.14 & 90.38 & 85.62 & 80.87 & 76.11 & 71.36 & 66.60 & 61.84 & 57.08 & 52.32 & 47.57 \\
\hline 18 & 102.86 & 97.72 & 92.58 & 87.43 & 82.29 & 77.15 & 72.00 & 66.86 & 61.72 & 56.57 & 51.43 \\
\hline 15 & 86.98 & 82.63 & 78.28 & 73.93 & 69.58 & 65.23 & 60.88 & 56.53 & 52.19 & 47.84 & 43.49 \\
\hline 12 & 71.38 & 67.81 & 64.24 & 60.67 & 57.10 & 53.53 & 49.97 & 46.40 & 42.83 & 39.26 & 35.77 \\
\hline 9 & 67.54 & 64.16 & 60.79 & 57.41 & 54.03 & 50.65 & 47.28 & 43.90 & 40.52 & 37.15 & 33.77 \\
\hline 6 & 50.56 & 48.04 & 45.51 & 42.98 & 40.45 & 37.92 & 35.39 & 32.87 & 30.34 & 27.81 & 25.28 \\
\hline 3 & 35.87 & 34.08 & 32.28 & 30.49 & 28.69 & 26.90 & 35.11 & 23.31 & 21.52 & 19.73 & 17.93 \\
\hline
\end{tabular}

Based on Table 3, the $127.43 \mathrm{~N}$ value is obtained as the wind load that occurs at the top of the tower with a height of 30 -meters, with the wind direction at $6^{\circ}$, as well as the value of $34.080 \mathrm{~N}$ is the wind load that occurs at the top of the tower with a height of 3 meters and the value 0 (zero) no force occurs. Graphically it is shown in Figure 8(b).

The wind load on a square tower. The wind load that occurs by the influence of the direction of the wind load is a variable according to where the direction of the wind is coming from, in the direction of the triangle tower the direction of the wind coming from any direction has no effect. This is because the triangle tower does not get a widening of the frame when viewed from all angles. For square towers will be described and explained in the following Table 4.

Based on Table 4, the cable-strength values for each cable are obtained and for $\Sigma \mathrm{N}$ is $1235.56 \mathrm{~N}$. This value is the largest value and will be used to calculate the resultant value (R). In addition to the greatest value, there are also other values adjusted to the wind direction, so that there are differences between each cable. This table is a very important part because in this section the primary moment obtained based on $\mathrm{M}_{\text {primary }}$ divided by the distance and angle that occurs.

The force influence of wind load on a square tower. The force caused by the influence of the direction of the wind load is a variable according to where the wind direction comes from, if it comes from $0^{\circ}$ then the wind will be borne $100 \%$ by cable-strength, and so on the wind load will be divided according to the degree of the coming wind direction. For square towers will be described and explained in the following Table 5.

Based on Table 5, then the value obtained is $189.70 \mathrm{~N}$ is the wind load that occurs at the top of the tower with a height of 30 -meters, with the wind direction at $45^{\circ}$, as well as the value of $50.73 \mathrm{~N}$ is the wind load that occurs at the top of the tower with a height of 3 meters and value 0 (zero) does not influence the wind load. Graphically it is shown in Figure 8(c).

Wind load on a square tower. The wind load that occurs by the influence of the direction of the wind load is a variable according to where the direction of the wind comes from, if it comes from $0^{\circ}$ then the wind load will be borne $100 \%$ by cable-strength, so onwards the wind load will be divided according to the degree of the direction of the wind, on the tower square wind direction will come only up to $45^{\circ}$. For square towers will be described and explained in the following Table 6.

Based on Table 6, the value of $180.21 \mathrm{~N}$ is obtained as the wind load that occurs at the top of the tower with a height of 30 -meters, with the wind direction at $45^{\circ}$, as well as the value of $48.19 \mathrm{~N}$ is the wind load that occurs at the top of the tower with a height of 3 meters and the value 0 (zero) no force occurs. Graphically it is shown in Figure 8(d).

The data that has been analyzed as above, then it would be nice if the data is illustrated in a graphic illustration, thus it will be illustrated as follows (Figure 8). 
Table 4. Primary moments in the square type. Source: Self-elaboration.

Compressive strength and degree of wind direction

\begin{tabular}{|c|c|c|c|c|c|c|c|c|c|c|c|c|c|c|c|c|c|}
\hline \multirow[b]{2}{*}{$\begin{array}{l}\text { Distance, } \\
\text { m (a) }\end{array}$} & \multirow[b]{2}{*}{$\begin{array}{l}\text { Segment, } \\
\mathrm{m}(\mathrm{b})\end{array}$} & \multirow[b]{2}{*}{$\begin{array}{l}\text { Radius, } \\
\mathrm{m}(\mathrm{R})\end{array}$} & \multicolumn{2}{|c|}{ Angle } & \multicolumn{11}{|c|}{$\begin{array}{l}\text { Compressive strength and degree of wind direction } \\
M_{\text {primery }}\left(3 / 4 h \times W_{0-10}\right)\end{array}$} & \multirow{2}{*}{$\begin{array}{c}\text { Mangl } \\
\text { e ( } \beta x \\
\text { h) }\end{array}$} & \multirow{2}{*}{$\begin{array}{c}\text { Cable } \\
\text { strength, } \\
\text { (M Mrimary } \\
0^{\circ} / M_{\text {angle }} \text { ) }\end{array}$} \\
\hline & & & $\operatorname{Sin} \alpha^{\circ}$ & $\begin{array}{l}\text { Radians } \\
\alpha^{\circ}(\mathrm{Rd})\end{array}$ & $0^{\circ}$ & $4.5^{\circ}$ & $9^{\circ}$ & $13.5^{\circ}$ & $18^{\circ}$ & $22.5^{\circ}$ & $27^{\circ}$ & $31.5^{\circ}$ & $36^{\circ}$ & $40.5^{\circ}$ & $45^{\circ}$ & & \\
\hline 6 & 30 & 30.59 & 11.31 & 0.19 & 112.32 & 109.03 & 105.73 & 102.41 & 99.10 & 95.49 & 92.18 & 89.18 & 85.88 & 82.57 & 79.26 & 0.59 & 189.69 \\
\hline 6 & 27 & 27.65 & 12.52 & 0.21 & 112.32 & 109.03 & 105.73 & 102.41 & 99.10 & 95.49 & 92.18 & 89.18 & 85.88 & 82.57 & 79.26 & 0.65 & 171.24 \\
\hline 6 & 24 & 24.73 & 14.03 & 0.24 & 112.32 & 109.03 & 105.73 & 102.41 & 99.10 & 95.49 & 92.18 & 89.18 & 85.88 & 82.57 & 79.26 & 0.73 & 152.85 \\
\hline 6 & 21 & 21.84 & 15.94 & 0.27 & 112.32 & 109.03 & 105.73 & 102.41 & 99.10 & 95.49 & 92.18 & 89.18 & 85.88 & 82.57 & 79.26 & 0.83 & 134.55 \\
\hline 6 & 18 & 18.97 & 18.43 & 0.32 & 140.42 & 136.28 & 132.15 & 128.02 & 123.88 & 119.75 & 115.61 & 111.48 & 107.35 & 103.21 & 99.08 & 0.96 & 145.47 \\
\hline 6 & 15 & 16.15 & 21.80 & 0.38 & 140.42 & 136.28 & 132.15 & 128.02 & 123.88 & 119.75 & 115.61 & 111.48 & 107.35 & 103.21 & 99.08 & 1.14 & 123.01 \\
\hline 6 & 12 & 13.41 & 26.56 & 0.46 & 140.42 & 136.28 & 132.15 & 128.02 & 123.88 & 119.75 & 115.61 & 111.48 & 107.35 & 103.21 & 99.08 & 1.39 & 100.95 \\
\hline 6 & 9 & 10.81 & 33.69 & 0.58 & 168.50 & 163.54 & 158.58 & 153.63 & 148.66 & 143.70 & 138.74 & 133.78 & 128.82 & 123.86 & 118.90 & 1.76 & 95.52 \\
\hline 6 & 6 & 8.48 & 45.00 & 0.78 & 168.50 & 163.54 & 158.58 & 153.63 & 148.66 & 143.70 & 138.74 & 133.78 & 128.82 & 123.86 & 118.90 & 2.35 & 71.51 \\
\hline 6 & 3 & 6.70 & 63.43 & 1.10 & 168.50 & 163.54 & 158.58 & 153.63 & 148.66 & 143.70 & 138.74 & 133.78 & 128.82 & 123.86 & 118.90 & $\begin{aligned} 3.32 \\
\Sigma N\end{aligned}$ & $\begin{array}{r}50.73 \\
1235.56\end{array}$ \\
\hline
\end{tabular}

Table 5. Force influence of wind direction on a square tower. Source: Self-elaboration.

\begin{tabular}{|c|c|c|c|c|c|c|c|c|c|c|c|}
\hline \multirow{2}{*}{$\begin{array}{l}\text { Segment, } \\
\text { m (b) }\end{array}$} & \multicolumn{11}{|c|}{ Force influence of wind direction on a square tower, $\mathrm{N}$ (Newton) } \\
\hline & $0^{\circ}$ & $4.5^{\circ}$ & $9^{\circ}$ & $13.5^{\circ}$ & $18^{\circ}$ & $22.5^{\circ}$ & $27^{\circ}$ & $31.5^{\circ}$ & $36^{\circ}$ & $40.5^{\circ}$ & $45^{\circ}$ \\
\hline 30 & 189.70 & 184.11 & 178.53 & 172.95 & 167.36 & 161.78 & 156.19 & 150.61 & 145.02 & 139.44 & 133.86 \\
\hline 27 & 171.24 & 166.20 & 161.16 & 156.12 & 151.08 & 146.04 & 141.0 & 135.96 & 130.92 & 125.87 & 120.83 \\
\hline 24 & 152.85 & 148.35 & 143.85 & 139.35 & 134.85 & 130.35 & 125.86 & 121.36 & 116.86 & 112.36 & 107.86 \\
\hline 21 & 134.55 & 130.59 & 126.63 & 122.67 & 118.71 & 114.75 & 110.79 & 106.83 & 102.86 & 98.90 & 94.94 \\
\hline 18 & 145.48 & 141.19 & 136.91 & 132.63 & 128.35 & 124.06 & 119.78 & 115.5 & 111.22 & 106.93 & 102.65 \\
\hline 15 & 123.01 & 119.39 & 115.77 & 112.15 & 108.53 & 104.91 & 101.29 & 97.66 & 94.04 & 90.42 & 86.80 \\
\hline 12 & 100.95 & 97.98 & 95.01 & 92.03 & 89.06 & 86.09 & 83,12 & 80.15 & 77.17 & 74.20 & 71.23 \\
\hline 9 & 95.52 & 92.71 & 89.90 & 87.08 & 84.27 & 81.46 & 78.65 & 75.84 & 73.02 & 70.21 & 67.40 \\
\hline 6 & 71.51 & 69.41 & 67.30 & 65.2 & 63.09 & 60.99 & 58.88 & 56.77 & 54.67 & 52.56 & 50.46 \\
\hline 3 & 50.73 & 49.23 & 47.74 & 46.25 & 44.75 & 43.26 & 41.77 & 40.27 & 38.78 & 37.79 & 35.79 \\
\hline
\end{tabular}

\begin{tabular}{|c|c|c|c|c|c|c|c|c|c|c|c|}
\hline \multirow{3}{*}{$\begin{array}{l}\text { Segment, } \\
\mathrm{m}(\mathrm{b})\end{array}$} & \multirow{3}{*}{$\begin{array}{c}\text { Cable } \\
\text { strength } \\
0^{\circ},(\mathrm{N})\end{array}$} & \multicolumn{10}{|c|}{ The Square tower cable-strength influence on the direction of the wind load (Cs) } \\
\hline & & $4.5^{\circ}$ & $9^{\circ}$ & $13.5^{\circ}$ & $18^{\circ}$ & $22.5^{\circ}$ & $27^{\circ}$ & $31.5^{\circ}$ & $36^{\circ}$ & $40.5^{\circ}$ & $45^{\circ}$ \\
\hline & & 5 & 10 & 15 & 20 & 25 & 30 & 35 & 40 & 45 & 50 \\
\hline 30 & 189.70 & 180.21 & 170.72 & 161.24 & 151.75 & 142.27 & 132.78 & 123.30 & 113.81 & 104.33 & 94.84 \\
\hline 27 & 171.24 & 162.68 & 154.11 & 145.55 & 136.99 & 128.43 & 119.87 & 111.30 & 102.74 & 94.18 & 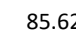 \\
\hline 24 & 152.85 & 145.21 & 137.56 & 129.92 & 122.28 & 114.64 & 106.99 & 99.35 & 91.71 & 84.06 & 76.42 \\
\hline 21 & 134.55 & 127.82 & 121.09 & 114.36 & 107.64 & 100.91 & 94.18 & 87.45 & 80.73 & 74.00 & 67.27 \\
\hline 18 & 145.48 & 138.20 & 130.92 & 123.65 & 116.38 & 109.10 & 101.83 & 94.56 & 87.28 & 80.01 & 72.73 \\
\hline 15 & 123.01 & 116.86 & 110.71 & 104.56 & 98.41 & 92.25 & 86.10 & 79.95 & 73.80 & 67.65 & 61.50 \\
\hline 12 & 100.95 & 95.90 & 90.85 & 85.81 & 80.76 & 75.71 & 70.66 & 65.62 & 60.57 & 55.52 & 50.47 \\
\hline 9 & 95.52 & 90.74 & 85.97 & 81.19 & 76.41 & 71.64 & 66.86 & 62.09 & 57.31 & 52.53 & 47.76 \\
\hline 6 & 71.51 & 67.94 & 64.36 & 60.78 & 57.21 & 53.63 & 50.06 & 46.48 & 42.91 & 39.33 & 35.75 \\
\hline 3 & 50.73 & 48.19 & 45.65 & 43.12 & 40.58 & 38.04 & 35.51 & 32.97 & 30.44 & 27.90 & 25.36 \\
\hline
\end{tabular}



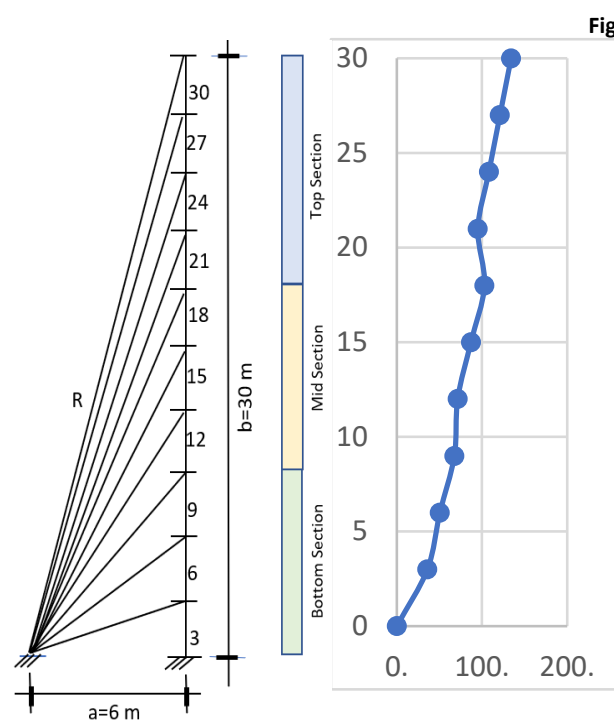

Figure 8. The chart analysis, Source: Self-elaboration.
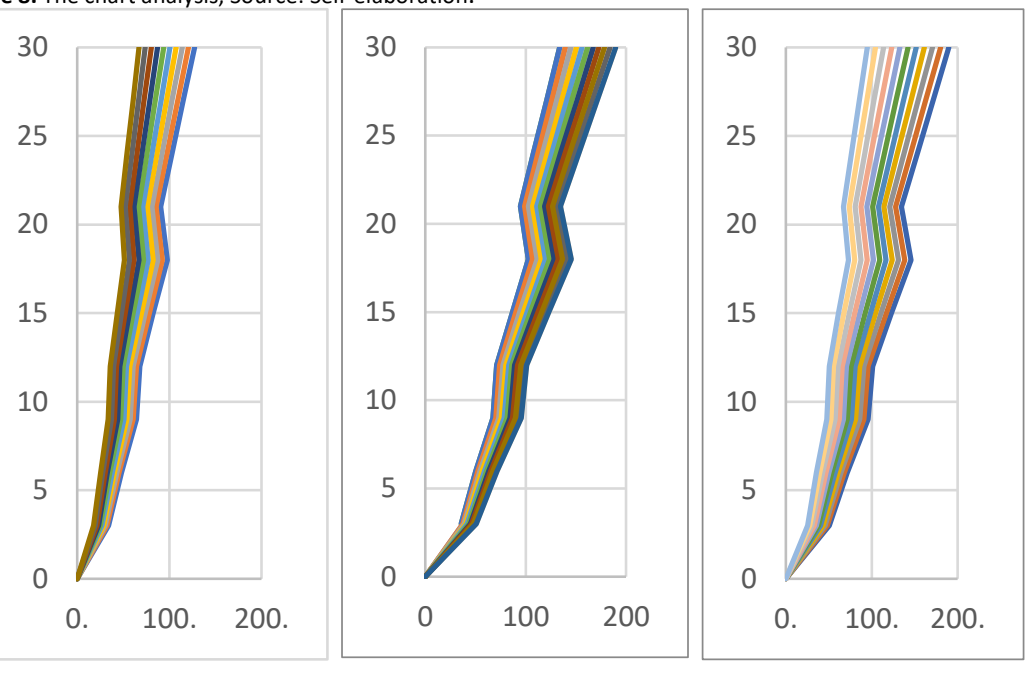

Based on Figure 8 as an illustration, graph that reflects wind loads on a triangle-tower, a value of $134.13 \mathrm{~N}$ is a wind load that occurs at the top of a tower with a height of 30 -meters, a value of $35.87 \mathrm{~N}$ is a wind load that occurs at the top of the tower with a height of 3 meters and a value of 0 (zero) there is no influence of the wind load.

In Figure $8(\mathrm{~b})$ is an illustrative graph that reflects the influence force of the wind direction load on the triangle-tower, the value $127.43 \mathrm{~N}$ is the wind load that occurs at the top of the tower with a height of 30 -meters, with the wind direction at $60^{\circ}$, as well as the value 34.080 is the wind load that occurs at the top of the tower with a height of 3 meters and a value of 0 (zero) does not occur force.

In Figure $8(\mathrm{c})$ is a graphic illustration that reflects the wind direction load on the square tower, the value $184.11 \mathrm{~N}$ is the wind load that occurs at the top of the tower with a height of 30-meters, with the wind direction at $45^{\circ}$, likewise the value of $49.23 \mathrm{~N}$ is wind load that occurs at the top of the tower with a height of 3 meters and a value of 0 (zero) does not occur the influence of the wind load.

In Figure $8(\mathrm{~d})$ is an illustrative graph that reflects the force influence of wind direction loads on a square tower, a value of $94,84 \mathrm{~N}$ is a wind load that occurs at the top of a tower with a height of 30 -meters, with wind direction at $45^{\circ}$, as well as a value of $25,36 \mathrm{~N}$ is a wind load that occurs at the top of the tower with a height of 3 meters and a value of 0 (zero) does not occur force.

The resultant angle on the triangle tower. As a result of the forces that occur in each cable-strength and with each direction and a different angle, the forces will form a resultant angle, with the description in the table as follows (Table 7).

Table 7. The resultant force on the Triangle tower. Source: Self-elaboration.

\begin{tabular}{|c|c|c|c|c|c|c|c|c|c|c|c|}
\hline \multirow[b]{2}{*}{$\begin{array}{c}\text { Segment, } \\
\mathrm{m}(\mathrm{b})\end{array}$} & \multirow{2}{*}{$\begin{array}{c}\text { Cable } \\
\text { strength } \\
(\mathrm{N})\end{array}$} & \multicolumn{2}{|c|}{ Angle } & \multicolumn{4}{|c|}{ Angle Resultant } & \multicolumn{4}{|c|}{ Angle Result } \\
\hline & & $\operatorname{Sin} \alpha^{\circ}$ & $\begin{array}{c}\text { Radians } \\
\alpha^{\circ}(\mathrm{Rd})\end{array}$ & $\cos \beta^{\circ}$ & $\begin{array}{c}\text { Radians } \\
\beta^{\circ}(\theta)\end{array}$ & $(\mathrm{Rx})$ & (Ry) & $\begin{array}{c}\text { Strengt } \\
\text { (Rxy) }\end{array}$ & $(\mathrm{Rxy}) \mathrm{X}^{\circ}$ & $(\mathrm{R} x y) \mathrm{Y}^{\circ}$ & $\begin{array}{c}\text { Control } \\
\theta^{\circ}\end{array}$ \\
\hline 30 & 134.13 & 11.31 & 0.19 & 78.69 & 1.37 & 184.22 & 26.47 & & & & \\
\hline 27 & 121.08 & 12.52 & 0.21 & 77.47 & 1.35 & 163.72 & 26.47 & & & & \\
\hline 24 & 108.08 & 14.03 & 0.24 & 75.96 & 1.32 & 143.29 & 26.47 & & & & \\
\hline 21 & 95.14 & 15.94 & 0.27 & 74.05 & 1.29 & 122.97 & 26.47 & & & & \\
\hline 18 & 102.86 & 18.43 & 0.32 & 71.56 & 1.24 & 128.48 & 33.09 & & & & \\
\hline 15 & 86.98 & 21.80 & 0.38 & 68.19 & 1.19 & 103.53 & 33.09 & & & & \\
\hline 12 & 71.38 & 26.56 & 0.46 & 63.43 & 1.10 & 79.03 & 33.09 & & & & \\
\hline 9 & 67.54 & 33.69 & 0.58 & 56.30 & 0.98 & 66.38 & 39.71 & & & & \\
\hline 6 & 50.56 & 45.00 & 0.78 & 45.00 & 0.78 & 39.71 & 39.71 & & & & \\
\hline \multirow[t]{2}{*}{3} & 35.87 & 63.43 & 1.10 & 26.56 & 0.46 & 16.63 & 39.71 & & & & \\
\hline & & & & & $\Sigma$ & 1048.00 & 324.35 & 1097.05 & 72.80 & 17.19 & 90.00 \\
\hline
\end{tabular}

Based on Table 7, the resultant force that occurs, lift force or vertical force of $1097,05 \mathrm{~N}$ with an angle of $72,80^{\circ}$ from the $\mathrm{X}$-axis and $17,19^{\circ}$ from the $\mathrm{Y}$-axis, then controlled according to an angle of $90^{\circ}$.

The vertical force and anchor dimension on the triangle tower. As a result of the forces that occur in each cable-strength and with each direction and a different angle, then the forces are converted into vertical force or lift force, then the lift 
force is held by the anchor with dimensions calculated and described in a table as follows (Table 8).

Table 8. The vertical force on a triangle tower. Source: Self-elaboration.

\begin{tabular}{|c|c|c|c|c|c|c|c|c|c|c|c|c|c|}
\hline \multirow{2}{*}{$\begin{array}{c}\text { Resultant } \\
\text { Strengt } \\
(\mathrm{Rxy})\end{array}$} & \multicolumn{6}{|c|}{ Angle Resultant } & \multicolumn{4}{|c|}{ Angle Result } & \multicolumn{3}{|c|}{ Anchor Dimension } \\
\hline & $\begin{array}{c}\text { (Rxy) } \\
\mathrm{X}^{\circ}\end{array}$ & $\begin{array}{c}\text { Radians } \\
\mathrm{Y}^{\circ}\end{array}$ & $\begin{array}{c}\text { (Rxy) } \\
Y^{\circ}\end{array}$ & $\begin{array}{c}\text { Radians } \\
\mathrm{X}^{\circ}\end{array}$ & $(\mathrm{Rxy}) \mathrm{X}^{\circ}$ & $\begin{array}{c}\text { (Rxy) } \\
Y^{\circ}\end{array}$ & $\begin{array}{l}\text { Vertical } \\
\text { Force }(\mathrm{N})\end{array}$ & $\begin{array}{c}\text { (Rxy) } \\
X^{\circ}\end{array}$ & $\begin{array}{c}\text { (Rxy) } \\
Y^{\circ}\end{array}$ & $\begin{array}{c}\text { Control } \\
\theta^{\circ}\end{array}$ & Discription & Value & Unit \\
\hline \multirow[t]{5}{*}{1097.05} & 72.80 & 1.27 & 17.19 & 0,30 & 1393.97 & 0.38 & 1393.87 & 89.98 & 0.016 & 90.00 & $\begin{array}{l}\text { Soil density } \\
\text { (sd) }\end{array}$ & 1000 & $\mathrm{Kg} / \mathrm{m}^{3}$ \\
\hline & & & & & & & & & & & Gravity (g) & 9.806 & $\mathrm{~m} / \mathrm{s}^{2}$ \\
\hline & & & & & & & & & & & $\begin{array}{l}\text { Depth of } \\
\text { anchor (h) }\end{array}$ & 1 & $\mathrm{~m}$ \\
\hline & & & & & & & & & & & $\begin{array}{l}\text { Anchor } \\
\text { Area (a) }\end{array}$ & 0,36 & $\mathrm{~m}^{2}$ \\
\hline & & & & & & & & & & & $\begin{array}{l}\text { Anchor load } \\
\text { (W) }\end{array}$ & $\begin{array}{r}3530 . \\
41\end{array}$ & Newton \\
\hline
\end{tabular}

Based on Table 8, the vertical force or lift force of $1393.97 \mathrm{~N}$ with an angle of $89.98^{\circ}$ from the X-axis and rounded to $90^{\circ}$. While the dimensions and size of the anchor that will withstand the lift force are with the following values: 1-meter value is the anchor depth, and the area of anchor landfilled is $0.36 \mathrm{~m}^{2}$. Based on these dimensions, it turns out that the force acting on the anchor is $3530,41 \mathrm{~N}>1393.97 \mathrm{~N}$ thus, the anchor dimension is declared safe.

The resultant angle on the square tower. As a result of the forces that occur in each cable-strength and with each direction and a different angle, the forces will form a resultant angle, with the description in the table as follows (Table 9).

Table 9. The resultant force on square tower. Source: Self-elaboration.

\begin{tabular}{|c|c|c|c|c|c|c|c|c|c|c|c|}
\hline \multirow[b]{2}{*}{$\begin{array}{l}\text { Segment, } \\
\text { m (b) }\end{array}$} & \multirow{2}{*}{$\begin{array}{l}\text { Cable } \\
\text { strength } \\
(\mathrm{N})\end{array}$} & \multicolumn{2}{|c|}{ Angle } & \multicolumn{4}{|c|}{ Angle Resultant } & \multicolumn{4}{|c|}{ Angle Result } \\
\hline & & $\operatorname{Sin} \alpha^{\circ}$ & $\begin{array}{c}\text { Radians } \\
\alpha^{\circ}(\mathrm{Rd})\end{array}$ & $\cos \beta^{\circ}$ & $\begin{array}{c}\text { Radians } \\
\beta^{\circ}(\theta)\end{array}$ & $(\mathrm{Rx})$ & (Ry) & $\begin{array}{c}\text { Strengt } \\
\text { (Rxy) }\end{array}$ & $(\mathrm{Rxy}) \mathrm{X}^{\circ}$ & $(\mathrm{Rxy}) \mathrm{Y}^{\circ}$ & $\begin{array}{c}\text { Control } \\
\theta^{\circ}\end{array}$ \\
\hline 30 & 189.70 & 11.31 & 0.19 & 78.69 & 1.37 & 260.53 & 37.44 & & & & \\
\hline 27 & 171.24 & 12.52 & 0.21 & 77.47 & 1.35 & 231.54 & 37.44 & & & & \\
\hline 24 & 152.85 & 14.03 & 0.24 & 75.96 & 1.32 & 202.65 & 37.44 & & & & \\
\hline 21 & 134.55 & 15.94 & 0.27 & 74.05 & 1.29 & 173.90 & 37.44 & & & & \\
\hline 18 & 145.48 & 18.43 & 0.32 & 71.56 & 1.24 & 181.70 & 46.80 & & & & \\
\hline 15 & 123.01 & 21.80 & 0.38 & 68.19 & 1.19 & 146.42 & 46.80 & & & & \\
\hline 12 & 100.95 & 26.56 & 0.46 & 63.43 & 1.10 & 111.77 & 46.80 & & & & \\
\hline 9 & 95.52 & 33.69 & 0.58 & 56.30 & 0.98 & 93.88 & 56.16 & & & & \\
\hline 6 & 71.51 & 45.00 & 0.78 & 45.00 & 0.78 & 56.16 & 56.16 & & & & \\
\hline 3 & 50.73 & 63.43 & 1.10 & 26.56 & 0.46 & 23.16 & 56.16 & & & & \\
\hline$\Sigma$ & 1235.56 & & & & & 1482.10 & 458.71 & 1551.46 & 72.80 & 17.19 & 90.00 \\
\hline
\end{tabular}

Based on Table 9, the resultant force that occurs, lift force or vertical force of $1551,46 \mathrm{~N}$ with an angle of $72,80^{\circ}$ from the $\mathrm{X}$-axis and $17.19^{\circ}$ from the $\mathrm{Y}$-axis, then controlled according to an angle of $90^{\circ}$.

The vertical force and anchor dimension on the square tower. As a result of the forces that occur in each cable-strength and with each direction and a different angle, then the forces are converted into vertical force or lift force, then the lift force is held by the anchor with dimensions calculated and described in a table as follows (Table 10).

\begin{tabular}{|c|c|c|c|c|c|c|c|c|c|c|c|c|c|}
\hline \multirow[b]{2}{*}{$\begin{array}{l}\text { Resultant } \\
\text { Strengt (Rxy) }\end{array}$} & \multicolumn{6}{|c|}{ Angle Resultant } & \multicolumn{4}{|c|}{ Angle Result } & \multicolumn{3}{|c|}{ Anchor Dimension } \\
\hline & $(\operatorname{Rxy}) \mathrm{X}^{\circ}$ & $\begin{array}{c}\text { Radians } \\
Y^{\circ}\end{array}$ & $(R x y) Y^{\circ}$ & $\begin{array}{c}\text { Radians } \\
X^{\circ}\end{array}$ & $(R x y) X^{\circ}$ & $\begin{array}{c}\text { (Rxy) } \\
Y^{\circ}\end{array}$ & $\begin{array}{l}\text { Vertical } \\
\text { Force }(\mathrm{N})\end{array}$ & $(R x y) X^{\circ}$ & $(R x y) Y^{\circ}$ & $\begin{array}{c}\text { Control } \\
\theta^{\circ}\end{array}$ & Discription & Value & Unit \\
\hline \multirow[t]{5}{*}{1551.46} & 72.80 & 1.27 & 17.19 & 0.30 & 1971.37 & 0.38 & 1971.37 & 89.98 & 0.011 & 90.00 & $\begin{array}{c}\text { Soil density } \\
\text { (sd) }\end{array}$ & 1000 & $\mathrm{Kg} / \mathrm{m}^{3}$ \\
\hline & & & & & & & & & & & Gravity (g) & 9.806 & $\mathrm{~m} / \mathrm{s}^{2}$ \\
\hline & & & & & & & & & & & $\begin{array}{l}\text { Depth of } \\
\text { anchor (h) }\end{array}$ & 1 & $\mathrm{~m}$ \\
\hline & & & & & & & & & & & $\begin{array}{l}\text { Anchor } \\
\text { Area (a) }\end{array}$ & 0,36 & $m^{2}$ \\
\hline & & & & & & & & & & & $\begin{array}{l}\text { Anchor load } \\
\text { (W) }\end{array}$ & $\begin{array}{r}3530.4 \\
1\end{array}$ & Newton \\
\hline
\end{tabular}

Based on Table 10, the vertical force or lift force of $1971.37 \mathrm{~N}$ with an angle of 89,98 from the X-axis and rounded to $90^{\circ}$. While the dimensions and size of the anchor that will withstand the lift force are with the following values: 1-meter value is the anchor depth, and the area of anchor landfilled is $0.36 \mathrm{~m}^{2}$. Based on these dimensions, it turns out that the force acting on the anchor is $3530,41 \mathrm{~N}>1971.37 \mathrm{~N}$ thus, the anchor dimension is declared safe. In detail, construction drawings can be seen in Figure 9(a), 9(b). 


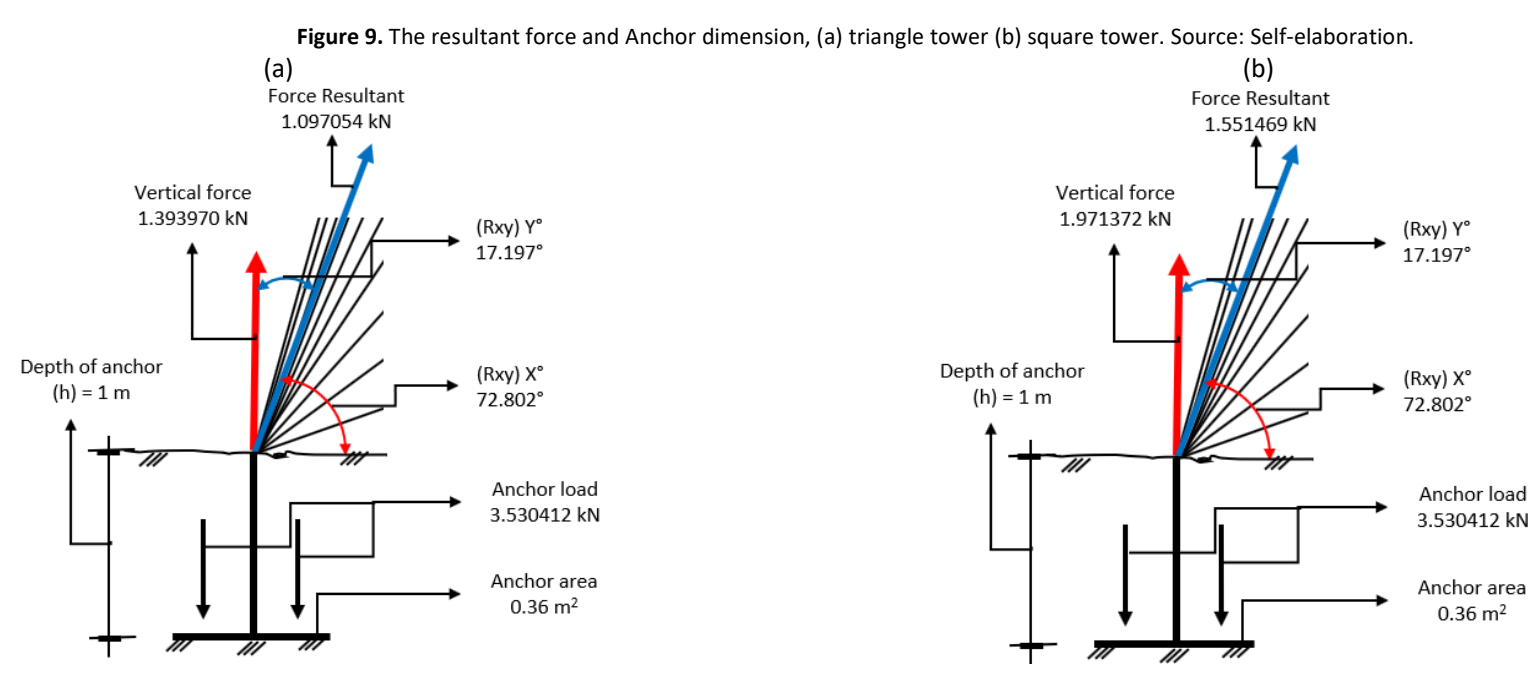

Based on Figure 9, the resultant angle that occurs is relatively the same, there is no difference between the Figure 9(a) and Figure $9(\mathrm{~b})$, this is because the angular division of the 10 tension cables is the same, both have the same height of 30-meters and each section is 3 meters each, the difference is in the force that occurs due to the influence of wind loads, so the vertical force that occurs in Figure $9(\mathrm{a})$ is $1393.97 \mathrm{~N}$ or $1.39397 \mathrm{kN}$ and Figure $9(\mathrm{~b})$ is $1971.37 \mathrm{~N}$ or $1.97137 \mathrm{kN}$. And for anchors, it also has the same dimensions of $0.36 \mathrm{~m}^{2}$.

\section{Conclusions}

The use of triangle antenna towers is more beneficial, because the wind load that occurs is smaller, thus the construction costs are also smaller. Due to the wind load that works horizontally and will be provided by the tower that stands vertically, the tower requires several retaining cables in a diagonal position, the force that propagates on the diagonal cable will cause a force in the vertical direction or lift, so the lift must be placed using anchors that are embedded in the soil, the large load from the soil that will hold the anchor is determined based on the value of the analysis, the criteria are too light so the anchor will be lifted and friendly, it will cause waste. The lifting power of a triangle antenna anchor tower is lighter around $1393.97 \mathrm{~N}$ or $1.39397 \mathrm{kN}$ than that of a square antenna anchor tower lift of around $1971.37 \mathrm{~N}$ or $1.97137 \mathrm{kN}$.

As a result of reducing the diameter of the rod, the cross-sectional area that holds the wind will decrease, as $W_{0}$, in table 3 , then the cable tension changes, so the curve in Figure $8(\mathrm{a})$ to $8(\mathrm{~d})$ is not linear. Thus it is strongly recommended to use the cross-section of the antenna tower frame more and leaner.

The force acting on a rod and held by a cable that has a certain angle, then the force will increase according to the angle formed. A set of forces acting on a cable with different angles will be held by a point, then the force will be transformed into a resultant force representing all of the sets of forces. The resultant force will be held to a vertical force by calculating the total force that occurs and the resultant angle of the force formed.

\section{Acknowledgements}

Special thanks to Mr. Prof. DR. Ir. H. I Gusti Ray Sudimantara, M.Agr as the Postgraduate Director of the University of Halu Oleo, who has provided much guidance, motivation and by promoting local wisdom and originating locally to build an era of 4 point zero that is more creative and innovative.

Alshurafa, S., \& Polyzois, D. (2018). Design recommendations and comparative study of FRP and steel guyed towers. Engineering Science and Technology, an International Journal, 21(5), 807-814. https://doi.org/10.1016/j.jestch.2018.06.014 www.elsevier.com/locate/jestch Full

Angadi, A. M., \& Prashanth, A. S. (2017). Design And Analysis Of Steel Tower Attachments For Domestic Wind Tower. Rnal of Engineering and Technology (IRJET), 422-428. www.irjet.net

Barsoum, I., \& Barsoum, F. (2012). Structural Analysis of a New Generation of Guyed Telecom Mast with a Wind Turbine. International Journal of Engineering and Technology (IJET), 2(9). 
Beer, F. P., E. Russell Johnston, J., Mazurek, D. F., \& Cornwell, P. J. (2013). Vector Mechanics For Engineers Statics And Dynamics. Mc Graw Hill Book Company. https://doi.org/www.mhhe.com

Bezrukovs, V., Upnere, S., Bezrukovs, V., Zacepins, A., \& Jekabsons, N. (2017). Effect of the Cellular Communication Mast Structure on the Wind Speed Measurement Results. International Journal of Contemporary ENERGY, 3(2), 41-49. https://doi.org/10.14621/ce.20170205

Bird, J., \& Ross, C. (2015). Mechanical Engineering Principles 3 ed. Routledge. https://doi.org/10.4324/9781315769806

Erdem, R. T. (2015). Analysis of guyed steel lattice mast subjected to environmental loads. GRAĐEVINAR, 67, 681-689. https://doi.org/10.14256/JCE.1181.2014

Luzardo, A. C., Parnás, V. E., \& Rodríguez, P. M. (2012). Guy tension influence on the structural behavior of a guyed mast. Journal Of The International Association For Shell And Spatial Structures: J. lass, February 2015. https://doi.org/https://www.researchgate.net/publication/272151204\%0AGuy

Marjanović, M., \& Petronijević, М. (2019). Design Of 120m Guyed Steel Mast In Alibunar According To Eurocode. ДГКМ ДРУШТВО НА ГРАДЕЖНИТЕ КОНСТРУКТОРИ НА МАКЕДОНИЈА asem.org/publication_conf/acem16/1.AWAS16/T4E.1.WS106_0724F1.pdf

Oliveira, M. I. R. De, Guilherme, J., Silva, S., Colmar, P., Vellasco, G. S., \& Andrade, S. A. L. De. (2007). Structural Analysis of Guyed Steel Telecommunication Towers for Radio Antennas. XXIX(2), 185-195.

Pezo, E., Gonçalves, P., \& Roehl, D. (2018). Non-linear finite element analysis of the dynamics of a slender cable stayed tower. MATEC Web of Conferences, 03001, 8-11. https://doi.org/https://doi.org/10.1051/matecconf/201814803001

Xiaowei, B., Yongtao, B., \& Qing, S. (2016). Numerical simulation on wind-induced responses of steel guyed transmission tower-line coupling systems. The 2016 World Congress on Advances in Civil, Environmental, and Materials Research (ACEM16). http://www.iasem.org/publication_conf/acem16/1.AWAS16/T4E.1.WS106_0724F1.pdf 